\title{
AVALIAÇÃO DO PERFIL DISCENTE QUANTO À FORMA DE ESTUDO, AO ALCANCE DOS OBJETIVOS DASDISCIPLINAS E PROBABILIDADE DE APROVAÇÃO.
}

\author{
RIO DE JANEIRO/RJ JULHO/2018
}

\author{
Rita de Cássia Borges de Magalhães Amaral - FSJ - ritaborges.amaral@uol.com.br \\ Armando Hayassy - FSJ - ahayassy@uol.com.br \\ Fernanda Nunes de Souza - FSJ - nandasouzanunes@gmail.com \\ Juan Lucas Nachez - UFF - jlnachez@gmail.com \\ Julle Anderson Moreira de Oliveira - FSJ - drjulleanderson@hotmail.com \\ Jessica Lage Moraes - FSJ - jessica.Imoraes@hotmail.com \\ William Chaia - FSJ - william.chaia@ig.com.br
}

Tipo: Investigação Científica (IC)

Natureza: Relatório Final de Pesquisa

Categoria: Pesquisa e Avaliação

Setor Educacional: EDUCAÇÃO SUPERIOR

\begin{abstract}
RESUMO
O presente trabalho objetivou diagnosticar as condições mais favoráveis ao aprendizado através de relatos de alunos da Faculdade de Odontologia das Faculdades São José, Rio de Janeiro, Brasil. Foi realizado um estudo com base em questionários sobre o desempenho dos discentes de diferentes períodos nas disciplinas já cursadas. Foram enviados 100 questionários com o auxílio de um aplicativo para comunicação dos quais 79 foram respondidos e 100 questionários foram aplicados em sala de aula dos quais 89 foram completamente preenchidos. Os participantes responderam os questionários fornecendo informações sobre cursos prévios, conclusão ou desistência, motivos e informações sobre a compatibilidade de suas notas com os seus métodos de estudo. Os dados foram tabulados e submetidos à análise estatística através de técnicas regressão logística binária que determinam a chance de ocorrência de um determinado evento. Neste trabalho, foram usados os valores de variáveis independentes para estimar a probabilidade de um aluno ser aprovado. Os entrevistados possuíam idade média de 27,23 + 7,13 anos, 44\% já cursaram outra faculdade, 54\% iniciaram e concluíram, 46\% iniciaram outro curso sem concluir, $57 \%$ dos alunos afirmam que suas notas estão compatíveis com os seus estudos, sendo que $20 \%$ dos alunos negam tal relação. A capacidade do aluno em assimilar o conteúdo e colocar em prática aumenta 1,8 vezes chances de ser aprovado e disponibilidade em mudar o seu método de estudo aumenta 3,5 vezes chance de aprovar. Portanto a prática de tecnologias metodológicas de aprendizagem que estimulem a disponibilidade do aluno em mudar o método de estudo aumentaria a aprovação do mesmo.
\end{abstract}

Palavras-chave: Aprendizagem, Educação Superior, Currículo 


\section{1- INTRODUÇÃO}

O Ensino nas faculdades de Odontologia no Brasil tem sofrido diversas mudanças, especialmente com a contínua introdução de novas tecnologias de ensino e inclusão de programas governamentais de financiamento. A mensuração do aprendizado é considerada um componente essencial da educação e a aquisição de destreza, conhecimento, processos afetivos e valores profissionais definem a competência prática na Odontologia. Além disso, os métodos de avaliação da acurácia de procedimentos desenvolvidos pelos alunos de graduação constituem um recurso útil tanto para a melhoria na qualidade do ensino como para a saúde daqueles que dependem desse serviço (SOUZA, 2011).

$\mathrm{Na}$ área da saúde, têm-se apontado caminhos inovadores para a capacitação e formação dos profissionais. Adotam-se, então, formas diferenciadas de ensinoaprendizagem e de organização curricular na perspectiva de interligar a teoria com a prática e o ensino com o serviço, além de desenvolver a capacidade reflexiva acerca de problemas reais e a formulação de ações originais e criativas capazes de modificar a realidade social (MARIN MSJ, 2010).

Diante destas mudanças pedagógicas, não se pode falar em aprendizagem sem ressaltar o papel do docente frente ao uso destas metodologias ativas de forma apropriada e contextualizada, mantendo-se em constante atualização para desempenhar sua função na construção de um ensino de qualidade (LEITE, 2012).

Há algum tempo se faz necessária a mudança nos currículos de odontologia no Brasil, com um modelo de ensino voltado ao mercado de trabalho na qual o estudante tenha a excelência técnica associada a um pensamento crítico. Litzinger (2011) afirma que uma das chaves para preparar os alunos no enfrentamento dos desafios profissionais é o exercício da construção de conhecimentos e habilidades que os tornem aptos a adaptação de problemas complexos, que serão encontrados em suas vidas profissional e pessoal.

É preciso modernizar a educação de modo que acompanhe as transformações ocorridas no mundo. Os métodos e os recursos do processo de ensino e aprendizagem são variados. Como as teorias precisam ser renovadas ou confirmadas permanentemente, para conduzir esta dinâmica, é necessário realizar uma contínua avaliação, a fim de acompanhar as descobertas científicas (FREITAS, 2009). 
diagnosticar as condições mais favoráveis ao aprendizado com base nos relatos de alunos de diferentes períodos da Faculdade de Odontologia das Faculdades São José, Rio de Janeiro, Brasil.

\section{2- METODOLOGIA DE ESTUDO}

O projeto foi aprovado pelo comitê de ética em pesquisa CAAE 55725416.0.0000.5259. Foi realizado um estudo descritivo exploratório com base em questionários sobre 0 desempenho de discentes de diferentes períodos nas disciplinas já cursadas e a que atribuíam o seu desempenho. Foram enviados 100 questionários com o auxílio de um aplicativo para comunicação (Whatsapp) e aplicados 100 questionários em sala. $O$ aplicativo utilizado permitiu avaliar se as mensagens enviadas foram visualizadas, se foram respondidas ou não foram respondidas. Os questionários em sala de aula nos permitiu avaliar a quantidade de alunos que quiseram responder, os alunos que se identificaram. Os dados foram tabulados quanto ao gênero, idade, compatibilidade das notas com a quantidade de estudo, da prática com os estudos, número de reprovações anteriores, motivo das reprovações e satisfação com o curso.

Após a tabulação dos dados foram calculadas as devidas porcentagens e os dados foram submetidos à análise estatística por técnicas de regressão logística.A análise de regressão foi realizada utilizando o software estatístico IBM SPSS Statistics.

As técnicas de regressão logística são técnicas versáteis que podem ser aplicadas em casos onde se deseja encontrar relações entre uma variável dependente (variável de resposta) e outras diferentes variáveis independentes. A regressão logística binaria pode ser usada para determinar a chance de ocorrência de um determinado evento. Neste trabalho, usamos os valores de uma série de variáveis independentes para estimar a probabilidade de um aluno ser aprovado uma disciplina (aprovar=1; reprovar $=0$ ).

Foram selecionadas perguntas do questionário, respondidas de forma binaria $(\operatorname{Sim}=1$; Não=0) para estimar a probabilidade de um aluno ser aprovado uma disciplina. As perguntas escolhidas avaliadas como variáveis independentes foram:

\section{- Gênero}

- Idade

- Você sente dificuldade em assimilar o conteúdo e colocar em prática?

- Você tem ou teve dificuldade em alguma matéria?

- Você concordaria em mudar o seu método de estudo?

- Você acha que o quanto você estuda está compatível com as suas notas? 


\section{3- RESULTADOS}

A pesquisa aplicada tem o objetivo em um interesse prático e seus resultados devem ser aplicados na solução de problemas reais. No que tange aos seus objetivos, esta pesquisa classificasse como descritiva, pois os dados utilizados na pesquisa foram registrados, não sofrendo nenhum tipo de alteração ou modificação, pois foram coletados e descritos no formato imparcial (PRODANOV e FREITAS, 2011).

Do total de 200 questionários 100 enviados e 100 entregues em sala de aula, 32 questionários não foram respondidos ou se apresentavam imcompletos, sendo um total de 168 questionários completamente respondidos, 79 via aplicativo (whatsapp) e 89 questionários entregues em sala de aula. A idade média entre os alunos que responderam foi $27,23 \pm 7,13$ anos. $44 \%$ já cursaram outra faculdade, $54 \%$ iniciaram e concluíram, $46 \%$ iniciaram outro curso mas não concluíram, $57 \%$ alunos afirmam que a prática está compatível com os seus estudos, entretanto, $20 \%$ dos alunos afirmam que suas notas não estão compatíveis com os seus estudos, $45 \%$ dos entrevistados nunca reprovaram, 55\% Reprovou em alguma matéria e 25\% mais de duas matérias. Dentre os resultados obtidos $48 \%$ não estão satisfeitos com o curso e $52 \%$ dizem estar satisfeitos, $55 \%$ afirma que precisa mudar sua forma de estudo, sendo que $75 \%$ concordaria em mudar, $45 \%$ diz que não precisa mudar sua forma de estudo e $25 \%$ não concordaria em mudar. Os resultados sugerem que o desenvolvimento de novas tecnologias metodológicas de aprendizagem para otimizar a qualidade do ensino em sala de aula, práticas clínicas e a prática de tecnologias metodológicas de aprendizagem que estimulem a disponibilidade do aluno em mudar o método de estudo aumentaria a aprovação do mesmo.

Regressão Logística:

\begin{tabular}{|c|c|}
\hline PERGUNTAS & Valor \\
\hline Gênero & 0,957 \\
\hline Idade & 0,992 \\
\hline $\begin{array}{c}\text { Você sente dificuldade em assimilar o } \\
\text { conteúdo e colocar em prática? }\end{array}$ & 1,798 \\
\hline $\begin{array}{c}\text { Você tem ou teve dificuldade em } \\
\text { alguma matéria? }\end{array}$ & 1,007 \\
\hline $\begin{array}{c}\text { Você concordaria em mudar o seu } \\
\text { método de estudo? }\end{array}$ & 3,571 \\
\hline $\begin{array}{c}\text { Você acha que o quanto você estuda } \\
\end{array}$ & 0,628 \\
\hline
\end{tabular}


está compatível com as suas notas?

Interpretação dos resultados:

Valores próximos e abaixo de 1 demonstra não fazer diferença na aprovação do aluno, portanto gênero, idade e ter dificuldade em alguma matéria não influenciam na aprovação.

Valores maiores que 1 aumentam a chance de aprovação. Assimilar o conteúdo e colocá-lo em prática aumenta em 1,8 vezes as chances de aprovar. Concordar em mudar o seu método de estudo aumenta 3,5 vezes chance de aprovar.

\section{4- CONSIDERAÇÕES FINAIS}

Os dados revelam que $59 \%$ dos entrevistados estudam por resumo próprio, $11 \%$ resumo de livro, $5 \%$ resumo de aula, $2 \%$ resumo do colega e $22 \%$ resumo de gravação da aula. Além de $42 \%$ dos alunos relatarem estudar na véspera das provas, $10 \%$ dos alunos estudam semanalmente e 5\% diariamente. Estes resultados revelam a urgência da adoção de uma metodologia de ensino que estimule os discentes a fazer buscas bibliográficas, leiam textos, busquem artigos científicos, capítulos de livros e, a partir do aprofundamento teórico, desenvolvam respostas e socializem em uma roda de diálogo o percurso de sua aprendizagem.

Neste sentido, os monitores fazem uso de assessoria presencial e não presencial, sendo estas o atendimento a alunos propriamente dito e o atendimento utilizando ferramentas ofertadas na graduação. Atualmente, é necessário que o professor ultrapasse a fundamentação técnica e fragmentada, para que possa agir em situações novas e problemáticas. O processo de atualização e formação docente se prolonga por todo seu trajeto profissional, mediante uma relação dialética na qual é defendida por Freire (2011) quando se coloca: "Quem ensina aprende ao ensinar quem aprende ensina ao aprender".

Chegando assim a conclusão que os $55 \%$ dos alunos insatisfeitos com seus estudos, não apresentam argumentos plausíveis para sua insatisfação, pois $88 \%$ utilizam método de estudo inadequado. Não lançando mão de artigos científicos e livros, não tendo assim base científica para contestar suas respostas consideradas incorretas. Os problemas financeiros não foram citados pelos entrevistados como fator impeditivo dos estudos. 
Entretanto, ainda são necessários estudos para observar os efeitos das Políticas de financiamento sobre a evasão, a retenção e na participação de projetos de monitoria e iniciação à pesquisa, pois o presente estudo não forneceu informações significativas para observar se os efeitos das Políticas de financiamento sobre a evasão. Observamos que de 50 alunos, apenas $20 \%$ nunca reprovaram, $22 \%$ já reprovaram no mínimo uma vez e $58 \%$ reprovaram mais de duas vezes. Dos $80 \%$ dos alunos já que já reprovaram, $77,5 \%$ assumem ter culpa direta por conta de falta de estudos, 17,5\% colocam a culpa nos docentes/ metodologia de ensino e na matéria, $5 \%$ afirmam ter reprovado por conta de problemas familiares e $2,5 \%$ diz ter tido problemas de saúde.

Os alunos não irão aprender estando simplesmente sentados em uma sala de aula ouvindo o professor, memorizando atribuições e disparando respostas vagas. Os estudantes devem dialogar, falar e argumentar sobre o que estão aprendendo, escrever sobre isso, relacionar com suas experiências e aplicar às suas vidas diariamente (RAO e DICARLO, 2000).

Uma das chaves para preparar os alunos no enfrentamento dos desafios profissionais é o exercício da construção de conhecimentos e habilidades que os tornem aptos à adaptação de problemas complexos, que serão encontrados em suas vidas profissional e pessoal (LITZINGER et al.,2011).

A necessidade de rompimento com o modelo de formação tradicional (clássico ou cartesiano) que vem há décadas sendo utilizado para a formação de profissionais da saúde, explica a amplitude e inovação que ganharam as discussões relacionadas ao emprego das metodologias ativas de ensino-aprendizagem nesse campo (SOBRAL, 2012).

Para Freitas (2009), os métodos de ensino ultrapassados podem não privilegiar a inteligência e a criatividade dos jovens, assim como, a eficiência da aprendizagem nas Universidades e na capacitação dos profissionais. Então, é preciso modernizar a educação para acompanhar as transformações ocorridas no mundo. Há uma imperiosa necessidade de mudanças no ensino para acompanhar as transformações na prática científica e na realidade contemporânea. O emprego das metodologias ativas na Odontologia pode ser influenciado pelo tipo da população-alvo, pela disponibilidade dos alunos para a aprendizagem e pela habilidade do professor em escolher uma metodologia apropriada ao que pretenda ensinar (SILVA, 2013). Portanto a prática de tecnologias metodológicas de aprendizagem que estimulem a disponibilidade do aluno em mudar o método de estudo pode aumentar a aprovação do mesmo. 


\section{5- REFERÊNCIAS}

FREIRE, Paulo. Pedagogia da Autonomia - Saberes Necessários à Prática Educativa. 43th ed. São Paulo: Paz e Terra, 2011.

FREITAS VP et al. Mudança no processo ensino - Aprendizagem nos cursos de graduação em odontologia com utilização de metodologias ativas de ensino e aprendizagem. RFO. 2009, 14(2):163-67.

LEITE C, RAMOS K. Formação para a docência universitária: uma reflexão sobre o desafio de humanizar a cultura científica. Revista Portuguesa de Educação. 2012, 25(1):7-27.

LITZINGER T et al. Newstetter W. Engineering Education and the Development of Expertise The research journal of enginering education. Volume 100, Issue 1 January 2011 Pages 123-150 DOI: 10.1002/j.2168-9830.2011.tb00006.x

MARIN MJS et al. Aspectos da Fortalezas e fragilidades no uso das metodologias ativas de aprendizagem. Rev Bras Educ Méd. 2010, 34 (1):13-20.

PRODANOV C. C; FREITAS E.C. Metodologia do Trabalho Científico: métodos e técnicas da pesquisa e do trabalho acadêmico. Novo Hamburgo: Feevale, 2009.

RAO S. P.; DICARLO S. N E. Peer instruction improves performance on quizzes. Advances in Physiology Education, v. 24, n. 1, p. 51-55, 2000.

SILVA KASR. A docência e seus desafios: um olhar crítico acerca da comercialização da educação. Rev Ciênc Hum. 2013, 6(1):107-19.

SOBRAL FR, CAMPOS CJG. The use of active methodology in nursing care and teaching in national productions: an integrative review. Rev Esc Enferm USP. 2012, 46(1):202-11.

SOUZA FN et al. Análise in vitro da adaptação de apoios em prótese parcial removível. Rev Flum de Odontol 2011; 36: 10-7. 